\title{
Dose-Related Modulation of Event-Related Potentials to Novel and Target Stimuli by Intravenous $\Delta^{9}-\mathrm{THC}$ in Humans
}

\author{
Deepak Cyril D'Souza*, 1,2,3,6, Daniel J Fridberg ',6, Patrick D Skosnik ${ }^{1,2,3}$, Ashley Williams ${ }^{1,2,3}$, Brian Roach ${ }^{4,5}$, \\ Nagendra Singh ${ }^{1,2,3}$, Michelle Carbuto ${ }^{1,2,3}$, Jacqueline Elander ${ }^{1,2,3}$, Ashley Schnakenberg ${ }^{1,2,3}$, \\ Brian Pittman $^{2,3}$, R Andrew Sewell ${ }^{1,2,3}$, Mohini Ranganathan ${ }^{1,2,3}$ and Daniel Mathalon ${ }^{3,4,5}$ \\ 'Psychiatry Senvice, VA Connecticut Healthcare System, West Haven, CT, USA; ${ }^{2}$ Abraham Ribicoff Research Facilities, Connecticut Mental Health \\ Center, New Haven, CT, USA; ${ }^{3}$ Department of Psychiatry, Yale University School of Medicine, New Haven, CT, USA; ${ }^{4}$ Department of Psychiatry, \\ University of California, San Francisco, San Francisco, CA, USA and ${ }^{5}$ Mental Health Service Line, San Francisco VA Medical Center, \\ San Francisco, CA, USA
}

\begin{abstract}
Cannabinoids induce a host of perceptual alterations and cognitive deficits in humans. However, the neural correlates of these deficits have remained elusive. The current study examined the acute, dose-related effects of delta-9-tetrahydrocannabinol ( $\Delta^{9}$-THC) on psychophysiological indices of information processing in humans. Healthy subjects $(n=26)$ completed three test days during which they received intravenous $\Delta^{9}$-THC (placebo, 0.015 and $0.03 \mathrm{mg} / \mathrm{kg}$ ) in a within-subject, double-blind, randomized, cross-over, and counterbalanced design. Psychophysiological data (electroencephalography) were collected before and after drug administration while subjects engaged in an event-related potential (ERP) task known to be a valid index of attention and cognition (a three-stimulus auditory 'oddball' P300 task). $\Delta^{9}$-THC dose-dependently reduced the amplitude of both the target P300b and the novelty P300a. $\Delta^{9}$-THC did not have any effect on the latency of either the P300a or P300b, or on early sensory-evoked ERP components preceding the P300 (the NI00). Concomitantly, $\Delta^{9}$-THC induced psychotomimetic effects, perceptual alterations, and subjective 'high' in a dose-dependent manner. $\Delta^{9}$-THC -induced reductions in P3b amplitude correlated with $\Delta^{9}$-THC-induced perceptual alterations. Lastly, exploratory analyses examining cannabis use status showed that whereas recent cannabis users had blunted behavioral effects to $\Delta^{9}$-THC, there were no dose-related effects of $\Delta^{9}$-THC on P300a/b amplitude between cannabis-free and recent cannabis users. Overall, these data suggest that at doses that produce behavioral and subjective effects consistent with the known properties of cannabis, $\Delta^{9}$-THC reduced P300a and P300b amplitudes without altering the latency of these ERPs. Cannabinoid agonists may therefore disrupt cortical processes responsible for context updating and the automatic orientation of attention, while leaving processing speed and earlier sensory ERP components intact. Collectively, the findings suggest that CBIR systems modulate top-down and bottom-up processing. Neuropsychopharmacology (2012) 37, 1632-1646; doi:10.1038/npp.2012.8; published online 15 February 2012
\end{abstract}

Keywords: $\Delta^{9}$-THC; cannabinoids; cannabis; P300; perception; psychosis

\section{INTRODUCTION}

Cannabis is the most widely used illicit substance worldwide (ONDCP, 2008; SAMHSA, 2011). Delta-9-tetrahydrocannabinol $\left(\Delta^{9}-\mathrm{THC}\right)$, the primary psychoactive constituent in cannabis, induces a range of perceptual alterations and cognitive deficits through the activation of brain cannabinoid receptors (CB1R) (reviewed in Ranganathan and D’Souza, 2006; Sewell et al, 2010). Electroencephalography (EEG) is one of the few available methodologies that can directly measure neural events (inhibitory and excitatory

*Correspondence: Dr DC D'Souza, Psychiatry Service, II6A, VA Connecticut Healthcare System, 950 Campbell Avenue, West Haven, CT 065 |6, USA, Tel: + I 203932 57| I × 2594, Fax: + I 203937 4860,

E-mail: deepak.dsouza@yale.edu

${ }^{6}$ Shared first authorship.

Received 19 October 201 I; revised 6 January 2012; accepted 8 January 2012 postsynaptic potentials; IPSPs and EPSPs, respectively) with high temporal precision in humans (Luck et al, 2011). Thus, the neural correlates of cannabinoids can be further elucidated utilizing EEG.

Event-related potentials (ERPs) are scalp recorded EEGs time-locked to stimuli or responses and averaged across trials (Luck et al, 2011). Several psychophysiological correlates of cognitive processes have been described in human ERP studies. In particular, the P300 component has been linked to a number of higher cognitive functions that are also known to be affected by cannabis (Sewell et al, 2010). The P300 wave is a positive voltage ERP component arising approximately $300 \mathrm{~ms}$ following the presentation of infrequent (oddball) stimuli during target detection tasks (reviewed in Polich, 2007; Polich and Criado, 2006). The target P300 (P300b) is elicited by infrequent task-relevant target stimuli and has a parietal scalp maximum. The P300b is associated with context updating and allocation of 
attentional resources, and is influenced by 'top-down' cognitive processes (reviewed in Polich, 2007). In contrast, the novelty P300 (P300a) is elicited by infrequent taskirrelevant stimuli and has a frontocentral scalp maximum. The P300a is thought to reflect 'bottom-up' processes involved in the automatic orienting of attention to novel or otherwise salient stimuli allowing for the rapid detection, evaluation, and adaptation to unexpected and potentially important changes in the environment (reviewed in Polich, 2007).

Reductions in P300 amplitude and increased latencies have been observed in a number of other neuropsychiatric disorders including schizophrenia and alcoholism (reviewed in Jeon and Polich, 2003; Polich and Criado, 2006; Porjesz et al, 2005). Converging lines of evidence suggest that multiple neural generators contribute to the P300b and P300a, including the hippocampus, frontal cortex, and parietal cortex (reviewed in Clarke et al, 1999; Polich, 2007). Importantly, these brain regions also have a high density of CB1Rs (Eggan and Lewis, 2007; Glass et al, 1997).

The literature pertaining to the effects of cannabinoids on the P300 have been predominantly based on cross-sectional comparisons of chronic cannabis users and controls. Reductions in P300 amplitude have been reported in studies utilizing cognitively challenging tasks (Kempel et al, 2003; Solowij et al, 1991). However, increased (Skosnik et al, 2008) or no differences in P300 amplitude have been reported in studies using classical oddball tasks (de Sola et al, 2008; Patrick et al, 1997; Patrick et al, 1995; Solowij et al, 1995). Mixed results have also been shown for P300 latency, as P300 latencies have been reported to be both increased (Kempel et al, 2003; Solowij et al, 1995) and decreased (de Sola et al, 2008) in cannabis users. These disparate results could be due to differences in task complexity, variability in stimulus parameters, the cross-sectional nature of studies in cannabis users, or the degree of cannabis exposure in subjects. Relevant to the latter, Hart et al (2010) emphasized the importance of accounting for cannabis exposure and examining multiple measures when investigating the neurocognitive effects of cannabis (Hart et al, 2010), as exposure to cannabis is associated with the development of tolerance (reviewed in Lichtman and Martin, 2005).

The acute administration of oral and smoked $\Delta^{9}$-THC has been reported to reduce $\mathrm{P} 300$ amplitude in the context of working memory or choice reaction time (RT) tasks (Hart et al, 2010; Ilan et al, 2005; Ilan et al, 2004; Roser et al, 2008). Furthermore, Roser and colleagues showed that polymorphisms in the CB1R gene altered the sensitivity to the acute effects of $\Delta^{9}$-THC on P300 generation (Stadelmann et al, 2011). Collectively, the results of genetic studies, acute $\Delta^{9}$-THC experiments, and studies of cannabis users suggest that $\mathrm{CB} 1 \mathrm{R}$ function may have an important role in the regulation of the $\mathrm{P} 300$.

There are several limitations to the existing literature, that we attempted to address in the current study. First, the effects of cannabinoids on subcomponents of the P300 (the P300a and P300b) during traditional 'oddball' tasks have not been examined. Second, oral and inhaled routes of administration of $\Delta^{9}$-THC have variable intra and interindividual pharmacokinetics (Azorlosa et al, 1995; Azorlosa et al, 1992; Grotenhermen, 2003). Furthermore, $\Delta^{9}$-THC cigarettes do not account for the effects of other components present in $\Delta^{9}$-THC cigarette smoke, which may contribute to the net effect of smoking $\Delta^{9}$-THC cigarettes. Herbal cannabis contains other cannabinoids eg, cannabidiol, which are known to have effects that could enhance or offset the effects of THC (Bhattacharyya et al, 2010). In addition, when pyrolyzed, THC-containing cigarettes release more than just THC. This is similar to the observation that compounds other than nicotine eg, betacarbolines alkaloids contribute to the psychoactive effects of tobacco smoke (Fowler et al, 1998; Guillem et al, 2005; Marti et al, 2011). Third, most experiments have assessed the acute effects of cannabinoids in chronic cannabis users, who are likely tolerant to the acute effects of $\Delta^{9}$-THC (D'Souza et al, 2008b; Ramaekers et al, 2009).

In order to address these limitations, we examined the acute, dose-related effects of intravenous (IV) $\Delta^{9}$-THC on both the P300b and P300a elicited during an auditory oddball paradigm. In order to assess early stimulus processing and registration, we also examined the N100 ERP component for both target and novel stimuli (Coull, 1998; Hillyard et al, 1973). Lastly, by studying participants with a range of exposure to cannabis, we explored whether exposure to cannabis influenced the behavioral and psychophysiological response to $\Delta^{9}$-THC.

\section{MATERIALS AND METHODS}

This randomized, double-blind, placebo-controlled, crossover study was conducted at the Neurobiological Studies Unit (Veteran Affairs Connecticut Healthcare System (VACHS), West Haven, CT, USA). Subjects were recruited by advertisements and by word of mouth, and were paid for their participation. The study was approved by the VACHS Human Studies Subcommittee and the Yale University School of Medicine (YUSM), and was carried out in accordance with the Helsinki Declaration of 1975. Subjects were informed about the potential for adverse effects of $\Delta^{9}$ THC including psychosis, anxiety, panic, and abuse liability.

\section{Subjects}

After obtaining written informed consent, subjects $(n=26$; 18-35 years) underwent a Structured Clinical Interview for DSM-IV (SCID) (First et al, 2002) and were carefully screened for any DSM Axis I lifetime psychiatric or substance use disorder (excluding tobacco and cannabis use) and family history of major Axis I disorder. Subjects were screened at a separate session within about 4 weeks of the first test day. All subjects were asked to estimate their lifetime cannabis exposure (\# times), heaviest exposure, and last exposure to cannabis. Cannabis-naïve individuals were excluded to minimize any risk of promoting future cannabis use/abuse. Subjects with DSM-IV cannabis dependence based on the SCID were excluded. The history provided by subjects was confirmed by a telephone interview conducted with a spouse or family member identified by the subject. A general physical and neurological examination, electrocardiogram, and laboratory tests (serum electrolytes, liver function tests, complete blood count with differential, urine toxicology, and urine pregnancy in women) were also conducted. After screening, subjects were instructed to refrain from alcohol, caffeinated beverages, illicit drugs 
(other than cannabis), or prescription drugs not approved by the research team for 2 weeks before the study and throughout study participation. Cigarette smokers were permitted to participate only if their pattern of cigarette consumption would allow them to abstain for each test day (0800-1500 hours) and their consumption did not exceed 10 cigarettes per day. Recent users of cannabis were instructed to abstain from smoking for at least $24 \mathrm{~h}$ prior to the test day. The test day was rescheduled if subjects reported using cannabis within $24 \mathrm{~h}$ of a test day. Subjects who were not categorized as recent users of cannabis were reminded not to use cannabis for 2 weeks before testing and throughout study participation. For this group, abstinence was confirmed by urine drug testing on the morning of each test day.

Subjects completed 3 test days during which they received $\Delta^{9}$-THC (vehicle (ethanol), $0.015 \mathrm{mg} / \mathrm{kg}$, or $0.03 \mathrm{mg} / \mathrm{kg}$ ) over $10 \mathrm{~min}$ by IV route in a randomized, counterbalanced order under double-blind conditions. Both staff and subjects received identical information without reference to any hypothesized group differences.

\section{Drugs}

The preparation, formulation, and storage of $\Delta^{9}$-THC solution are reported elsewhere (D'Souza et al, 2004). For the control condition, an equivalent volume of ethanol (vehicle) was used, which was previously shown to be undetectable in multiple post-injection blood samples (D'Souza et al, 2004). The IV route of administration was chosen to standardize the delivery of $\Delta^{9}$-THC as discussed previously (D'Souza et al, 2004).

\section{Plasma Levels}

At the $-60,+10,+80$, and +140 time points, blood was sampled from the IV line from the arm opposite to the one used for administering the study drug for determination of 11-nor- $\Delta$-9-THC-9-COOH (THC-COOH) and analyzed using the methods of Shaw et al (1991).

\section{Oddball (target) Behavioral Performance}

Behavioral performance measures for the oddball task included the percentage of correct responses to target stimuli (out of 45 total), and the median RT to targets.

\section{EEG Procedure and Acquisition}

In the three-stimulus auditory oddball task, a random series of infrequent $(8.33 \%)$ 'target' tones $(1000 \mathrm{~Hz})$, frequent $(83.33 \%)$ 'standard' click trains $(20,30$, or $40 \mathrm{~Hz})$, and infrequent task-irrelevant novel distractor sounds $(8.33 \%)$ were presented with a 1.25-s stimulus onset asynchrony in three separate blocks. Novel distractor sounds were selected from a corpus of sounds developed by Friedman et al, (1993), including a variety of natural and man-made sounds such as dog barks, car horns, human coughing, piano sounds, and so on. The target tones were $500 \mathrm{~ms}$ in duration and $80 \mathrm{~dB}$ SPL (C weighting). Novel distractor sounds ranged between 175 and $250 \mathrm{~ms}$ in duration and averaged $80 \mathrm{~dB}$ SPL (C weighting). Standard click trains were $500 \mathrm{~ms}$ in duration and $80 \mathrm{~dB}$ SPL (C weighting).
In each task block, subjects were asked to press a response key to the target stimuli with the index finger of their preferred hand. Each block comprised 15 targets, 15 distractor stimuli, and 150 standards $(20 \mathrm{~Hz}$ click train standards for block $1,30 \mathrm{~Hz}$ click train standards for block 2 , and $40 \mathrm{~Hz}$ click train standards for block 3 ). The order of blocks was randomized for each test day. In order to maximize ERP signal to noise ratio, target and novel distractor stimuli were separately averaged across all three blocks. Thus, in total, there were 45 targets, 45 novel distractors, and 450 standards for each participant on each test day (both pre- and post-drug infusion). ERPs and EEG responses to the standard click trains are not presented here, but will be the focus of a separate report.

Subjects sat in an acoustically shielded booth in front of a computer monitor and wore insert earphones (Etymotic Research, Elk Grove Village, IL, USA). EEGs were recorded at $1000 \mathrm{~Hz}$ from 26 scalp electrodes, bandpass filtered between $0.05-200 \mathrm{~Hz}$, and referenced to linked ears (Neuroscan SynAmps, Compumedics Neuroscan, Charlotte, NC, USA). Additional electrodes were placed at the outer canthi of both eyes, and above and below the left eye to record eye movements and blinks (vertical and horizontal electro-oculogram (EOG); VEOG, HEOG, respectively). All electrode impedances were maintained $\leqslant 10 \mathrm{k} \Omega$.

\section{ERP Analyses}

All EEG processing was performed as described previously (Mathalon et al, 2010). Briefly, EEG data from 3 midline sites $(\mathrm{Fz}, \mathrm{Cz}$ and $\mathrm{Pz})$ were analyzed. Continuous data were $12 \mathrm{~Hz}$ low-pass filtered then separated into $1000 \mathrm{~ms}$ epochs time-locked to stimulus onset, with a 100 -ms pre-stimulus baseline. VEOG and HEOG data were used to correct EEG for eye movements and blinks with a regression-based algorithm (Gratton et al, 1983). After baseline correction, epochs containing artifacts (voltages exceeding $\pm 100 \mu \mathrm{V}$ ) were rejected. All EEG data were collected at baseline, $30 \mathrm{~min}$ before drug infusion and $20 \mathrm{~min}$ after the infusion of $\Delta^{9}$-THC. The entire ERP experiment lasted $\sim 25 \mathrm{~min}$.

P300 peak latencies were identified as the most positive peak in a $250-400-\mathrm{ms}$ time window following stimulus onset. Target $\mathrm{P} 300 \mathrm{~b}$ peak was identified at $\mathrm{Pz}$, while novelty P300a peak was identified at $\mathrm{Cz}$. The somewhat early latency cut-off $(400 \mathrm{~ms})$ for auditory P300s was chosen to avoid picking the second late positive component, which peaked around $550 \mathrm{~ms}$. In a few cases where no local maximum was found in the search window, peaks were manually identified by investigators (DHM and BJR) blind to the subject's test day. Peak amplitudes for all midline sites were quantified as the microvolt value at the latency corresponding to the $\mathrm{Pz}$ peak for targets and to the $\mathrm{Cz}$ peak for novel distractors. P300b and P300a peak latencies for target and novel stimuli were only measured at $\mathrm{Pz}$ and $\mathrm{Cz}$, respectively, as that is where each type of P300 was largest (and thus where its peak latency was likely to be most accurate).

Analysis of the auditory N100 ERP to target and novel stimuli were performed in order to assess early stimulus processing and registration. Peak N100 amplitude and latency values were measured at each electrode based on automated algorithm that identified the most negative voltage between 50 and $120 \mathrm{~ms}$ after stimulus onset. All 
EEG and ERP processing was performed using commercially available software (BrainVision Analyzer, Brain Products $\mathrm{GmbH}$, Germany).

Intraclass correlation (ICC) coefficients were computed to examine the test-retest reliability of the amplitudes and latencies of the P300a (at Cz), P300b (at Pz), and N100 (at $\mathrm{Cz}$ ) obtained from the pre-administration recordings across all three testing days. For amplitude measures, the ICCs were moderately high (P300a ICC $=0.70, \mathrm{P} 300 \mathrm{~b}$ ICC $=0.84$, Target N100 ICC $=0.66$, and Novelty N100 ICC $=0.77)$. For latency measures, ICCs were more variable, with relatively low values for P300b $(\mathrm{ICC}=0.43)$, target $\mathrm{N} 100(\mathrm{ICC}=0.32)$ and novelty $\mathrm{N} 100(\mathrm{ICC}=0.39)$, and a relatively high value for P300a $(\mathrm{ICC}=0.86)$.

\section{Behavioral and subjective measures}

In order to confirm $\Delta^{9}$-THC effects and examine possible associations between the psychophysiological, and the behavioral and subjective effects of exogenous cannabinoids, several outcome measures known to be sensitive to the effects of $\Delta^{9}$-THC (D'Souza et al, 2008a; D'Souza et al, 2004; D'Souza et al, 2008b) were also included. Perceptual alterations were measured using the self- and clinicianadministered subscales of the Clinician Administered Dissociative Symptoms Scale (CADSS)(Bremner et al, 1998) consisting of 19 self-report items and 8 clinicianrated items rated from 0 (not at all) to 4 (extremely). The scale evaluates aspects of altered environmental perception, time perception, body perception, feelings of unreality, and memory impairment. Positive, negative, and general symptoms associated with schizophrenia were assessed using relevant subscales of the Positive and Negative Syndrome Scale (PANSS) (Kay et al, 1989). 'High' associated with cannabis intoxication was measured using a self-reported Visual Analog Scale (VAS) (0-100). These assessments were administered at baseline $(-60 \mathrm{~min}),+10$, and $+80 \mathrm{~min}$ time points, where time point $0 \mathrm{~min}$ denotes the beginning of the $\Delta^{9}$-THC infusion. The same research coordinators rated all 3 testing days for each subject. Interrater reliability sessions were conducted every 1-2 months over the time period ( $\sim 4$ years) that this study was conducted and, for example, intraclass correlation coefficients for the PANSS were consistently $>0.85$.

\section{General Procedure and Test Days (Supplemental Text 1:} Schedule of Procedures)

Test days were separated by 3 days to minimize carryover effects. Subjects fasted overnight, reported to the test facility around 0800 hours, and were provided a standard breakfast. Urine toxicology was conducted on the morning of each test day to rule out recent illicit drug use. A positive urine pregnancy test also resulted in exclusion. In-study safety procedures are described elsewhere (D'Souza et al, 2004). Vital signs were recorded at the $-60,+10,+50,+80$, +140 , and +200 min time points. A field sobriety test, mental state examination, and exit interview were conducted at the end of each test day, and an exit interview was conducted on the last test day. Prospective safety assessments were performed at 1 and 3 months after the last test session and after they had received payment for participa- tion to query their use of cannabis. As described in further detail elsewhere (Carbuto et al, 2011), subjects were asked to rate (not at all, slightly less, about the usual, slightly more, and much more) (1) whether their exposure to THC in the lab had changed their cannabis use, (2) how intense has their desire for cannabis has been since the last test day or questionnaire, and (3) how many times per week they had used cannabis since the last test day or questionnaire.

\section{Statistical Analysis}

Initially, data were examined descriptively using means, SD, and graphs. Each outcome was assessed for normality visually by histograms and measures of skewness and kurtosis.

ERP amplitudes were submitted to repeated-measures analysis of variance (ANOVA) using a dose $(3) \times$ time $(2$; pre-infusion, post-infusion) $\times$ electrode $(3 ; \mathrm{Fz}, \mathrm{Cz}, \mathrm{Pz})$ design. ERP component latencies which were assessed at the electrode at which the component amplitude was maximal, were analyzed by repeated-measures ANOVA using a dose (3) $\times$ time (2) design. In addition, to assess whether THC had differential effects on the amplitudes of the novelty P300a and target P300b, a dose $(3) \times$ time $(2) \times$ electrode $(3) \times$ stimulus type (2; targets, novels) repeated measures ANOVA was conducted. Degrees of freedom were adjusted using the Greenhouse-Geisser correction for all within-subject factors involving more than two levels. Effect sizes for repeated measures ANOVA were calculated as partial $\eta$-squares, where small effect sizes are $<0.06$, moderate effect sizes range from 0.06 to 0.14 , and large effect sizes are $>0.14$ (Cohen, 1973). Follow-up comparisons (ANOVAs and $t$-tests) were conducted as appropriate to clarify the source of significant interaction effects. Of primary interest were the effects of dose, time and interactions of dose $\times$ time on ERP measures. RTs to target stimuli during the oddball task were analyzed using repeated-measures ANOVA with the factors dose (3) and time (2). However, target accuracies (percentage of correct responses to targets) were not normally distributed and thus, were analyzed using a nonparametric method for repeated-measures data (Brunner et al, 2002) with dose (3) and time (2) as within-subjects factors. In this approach, the data were first ranked, and then fitted using a mixed effects model with an unstructured variance-covariance matrix and $p$-values adjusted for ANOVA-type statistics (ATS). Behavioral data were skewed and exhibited floor effects, as expected in this healthy control sample. Thus, similar nonparametric analyses with dose (3) and time (3: preinfusion, peak-infusion, and post-infusion) were conducted for the PANSS (total, negative, positive, and general scores), CADSS (clinician- and patient-rated scores), and VAS 'high' data. Post-hoc analyses were used to clarify the source of interaction effects. Spearman's correlation coefficients were calculated to examine possible associations between psychophysiological and behavioral measures. Exploratory analyses using a similar approach were conducted to examine whether effects differed between subgroups with or without recent cannabis use. To correct for multiple comparisons Bonferroni correction was applied within hypotheses, but not across hypotheses or for exploratory analyses. For example, a cutoff $\alpha$ level of $0.05 / 3=0.0167$ was 
used to declare effects significant for the between-dose posthoc comparisons for each PANSS subscale. Parametric and nonparametric analyses were conducted using the software package for PASW Statistics 18.0 and SAS version 9.1 (SAS Institute, Cary, NC, USA), respectively.

\section{RESULTS}

Demographic and cannabis use data are listed in Table 1. Of 56 subjects who were consented, 30 completed all 3 test days, 8 dropped out, 8 never initiated, and 10 were screen failures. Almost half the subjects (12 of 26) reported not having used cannabis in the past month. None of the subjects met criteria for alcohol or substance abuse or dependence. Due to technical difficulties during EEG acquisition, 4 subjects were excluded from the analyses.

\section{Oddball (Target) Performance Data}

Participants performed well on the oddball task overall, identifying $>96.7 \%$ of the target stimuli correctly across all three dosage conditions. Target accuracies were negatively skewed and were analyzed using nonparametric analysis. There were no significant effects of dose or time, and no significant dose $\times$ time interaction for percentage of correct responses to target stimuli (all $p>0.10$ ). For median RTs to targets, there were no significant effects of dose or time ( $p s>0.15)$, but there was a significant dose $\times$ time interaction, $(F(2,50)=3.64, p=0.033)$. Follow-up tests revealed a significant slowing of RT for the $0.03 \mathrm{mg} / \mathrm{kg} \Delta^{9}$-THC dose $\left(p=0.035\right.$, partial $\left.\eta^{2}=0.17\right)$, with no significant effects for placebo or for the $0.015 \mathrm{mg} / \mathrm{kg} \Delta^{9}$-THC dose ( $p s>0.31$ ).

The ERP results reported below focus on the effects of dose, time and dose $\times$ time interactive effects, since these were of primary interest. Other effects eg, electrode are reported in the table.

\section{Target P300b Amplitude}

Figure 1 shows the grand-averaged pre- and post-infusion ERP waveforms at electrode $\mathrm{Pz}$ and the ERP results reported below focus on the effects of dose, time and dose $\times$ time interactive effects, since these were of primary interest. Other effects eg, electrode are reported in the table (Figure 1; Table 2). Post-hoc comparisons revealed that P300b amplitude was significantly smaller post-infusion relative to the pre-infusion baseline in both of the active $\Delta^{9}$-THC conditions ( $p s<0.001)$, whereas post-infusion P300b amplitude did not differ from baseline in the placebo condition $(p=0.07)$ (Figure 2). Furthermore, $0.03 \mathrm{mg} / \mathrm{kg} \Delta^{9}$-THC was associated with a larger decrease in $\mathrm{P} 300 \mathrm{~b}$ amplitude relative to $0.015 \mathrm{mg} / \mathrm{kg} \Delta^{9}$-THC, $t(25)=3.27, p=0.003$.

\section{Target P300b latency}

There were no significant effects of dose $(p=0.25)$, time $(p=0.50)$, or their interaction $(p=0.90)$ for target $\mathrm{P} 300 \mathrm{~b}$ latency at $\mathrm{Pz}$.
Table I Sample Demographics

\begin{tabular}{|c|c|}
\hline \multicolumn{2}{|l|}{ General characteristics } \\
\hline No. male (female) & $17(9)$ \\
\hline Age (mean (SD)) & $25.92(7.84)$ \\
\hline Handedness & I left handed \\
\hline Years of education (mean (SD)) & $15.08(2.04)$ \\
\hline Estimated IQ (mean (SD)) & | I 5.77 (4.47) \\
\hline \multicolumn{2}{|l|}{ Cannabis exposure } \\
\hline Age of first cannabis use & $17.08(2.60)$ \\
\hline $\begin{array}{l}\text { Days since last use/last exposure } \\
\text { (mean (SD) range) }\end{array}$ & $\begin{array}{c}415.02 \\
(819 \pm 0.36) \\
(\text { range } 1-3650)\end{array}$ \\
\hline Total years of use (mean (SD) range) & $6.85( \pm 4.54) \mid-18$ \\
\hline Frequency of cannabis use within past 30 days (n) & No. of subjects \\
\hline 0 days & 12 \\
\hline I-3 days & 3 \\
\hline 4-8 days & 3 \\
\hline $9-15$ days & 5 \\
\hline 16-29 days & 2 \\
\hline Lifetime cannabis use (total no. of exposures) & No. of subjects \\
\hline $1-10$ & 5 \\
\hline $1 \mid-50$ & 7 \\
\hline $51-200$ & 3 \\
\hline $201-500$ & 4 \\
\hline $501-1000$ & 3 \\
\hline$>1000$ & 4 \\
\hline $\begin{array}{l}\text { Cannabis exposure during heaviest use } \\
\text { (no. of exposures) }\end{array}$ & No. of Subjects \\
\hline$>\mid$ to $\mid \times$ per year & 2 \\
\hline$I \times$ per every $3-6$ months & 4 \\
\hline $1-3 \times$ per month & 4 \\
\hline I-2 $\times$ per week & 4 \\
\hline $3-6 \times$ per week & 7 \\
\hline $7 \times$ per week & 5 \\
\hline \multicolumn{2}{|l|}{ Other drug exposure } \\
\hline Daily cigarette smokers (\# of subjects) & 3 \\
\hline Average no. of alcoholic drinks per week (mean (SD)) & $6.01(6.06)$ \\
\hline $\begin{array}{l}\text { Previous recreational exposure to illicit drugs other than } \\
\text { cannabis }\end{array}$ & No. of subjects \\
\hline None & 11 \\
\hline Hallucinogens & 12 \\
\hline Stimulants & 10 \\
\hline Opiates & 3 \\
\hline Inhalants & 2 \\
\hline
\end{tabular}

None of the subjects met criteria for abuse or dependence of the above illicit substances.

\section{Novelty P300a Amplitude}

Figure 3 shows the grand-average pre- and post-infusion ERP waveforms at electrode $\mathrm{Cz}$ and the novelty P300a 

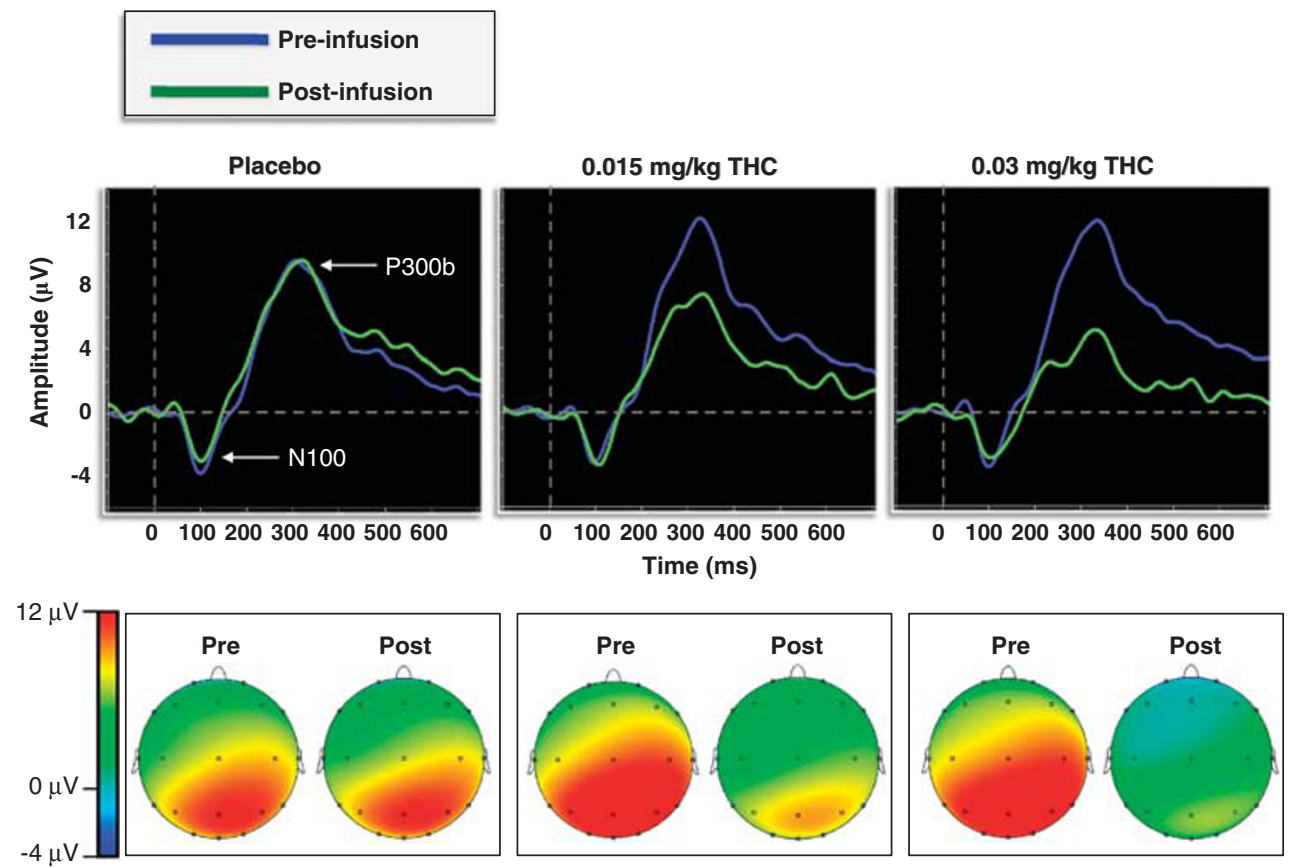

Figure I (Top) Grand-averaged target P300b waveforms at electrode Pz for both the pre- and post-infusion electroencephalography (EEG) runs across dose conditions. (Bottom) Topographic voltage maps from the peak grand-averaged P300b for both the pre- and post-infusion EEG runs across dose conditions.

topographic maps across $\Delta^{9}$-THC dose. There was a significant dose $\times$ time interaction for P300a amplitude to novel distractors, $\left(F(2,50)=7.29, p=0.003\right.$, partial $\left.\eta^{2}=0.23\right)$ (Figure 4; Table 2). Post-hoc comparisons revealed that P300a amplitude was significantly lower post-infusion relative to the pre-infusion baseline for both of the active $\Delta^{9}$-THC conditions $(p s<0.001)$ but not for placebo $(p=0.08)$. Moreover, the $0.03 \mathrm{mg} / \mathrm{kg} \Delta^{9}$-THC dose was associated with a trend towards a larger decrease in $\mathrm{P} 300 \mathrm{a}$ amplitude relative to the $0.015 \mathrm{mg} / \mathrm{kg} \Delta^{9}$-THC dose, $t(25)=1.97, p=0.06$. (Figure 4).

\section{Novelty P300a Latency}

There was no significant effect of dose $(p=0.53)$, time $(p=$ $0.13)$ or the dose $\times$ time interaction $(p=0.83)$ for $\mathrm{P} 300 \mathrm{a}$ latency at $\mathrm{Cz}$.

\section{Target P300b vs Novelty P300a Amplitude}

The 4-way ANOVA that included Stimulus Type (target vs novel) as a factor yielded no significant effects for dose $\times$ time $\times$ stimulus type $(F(2,50)=0.53, p=0.59)$ or dose $\times$ time $\times$ stimulus type $\times$ electrode $(F(2,100)=0.46, p=0.69)$, indicating that THC had similar effects on the amplitudes of target P300b and novelty P300a.

\section{Target N100 amplitude}

There were no significant effects of dose $(p=0.48)$, time $(p=0.2)$ or their interaction $(p=0.76)$ on N100 amplitude to target stimuli (Figure 5).

\section{Target N100 Latency}

There were no significant effects of dose $(p=0.36)$ or time $(p=0.7)$, and no dose $\times$ time interaction $(p=0.39)$ for N100 latency to target stimuli at $\mathrm{Cz}$.

\section{Novelty N100 Amplitude}

There were no significant effects of dose, time, and no dose $\times$ time interactions for $\mathrm{N} 100$ amplitude to novel stimuli (all ps >0.64) (Figure 5).

\section{Novelty N100 Latency}

There were no significant effects of dose $(p=0.5)$ or time $(p=0.28)$, or their interactions $(p=0.61)$ at $\mathrm{Cz}$.

\section{Behavioral and Subjective Data}

For all behavioral and subjective measures, the main analysis of interest was the dose $\times$ time interaction. Mean (SD) scores on the PANSS, CADSS, and VAS for each dose and time point are presented in Table 3 and Figure 6. For the behavioral measures described below, post-hoc comparisons were performed at the $10 \mathrm{~min}$ after infusion time point, as that is where the largest values on the behavioral and subjective measures were observed in the active dose conditions (Figure 6).

PANSS. There was a significant dose $\times$ time interaction for PANSS total scores (num $\mathrm{df}=3.34$, ATS $=27.2, p<0.0001$ ). Post-hoc comparisons revealed a dose-related effect of THC administration on PANSS total scores at $10 \mathrm{~min}$ after administration, such that placebo $<0.015 \mathrm{mg} / \mathrm{kg} \mathrm{THC}$ $<0.03 \mathrm{mg} / \mathrm{kg}$ THC (all $p s<0.001$ ). Separate analyses were 
Table 2 Main Effects and Interactions for RMANOVAs of ERP Amplitudes

\begin{tabular}{llllll}
\hline ERP & Source & df & $F$ & $p$ & Partial $\eta^{2}$
\end{tabular}

P3b-targets

$\begin{array}{lcccc}\text { Dose } & 2 & 1.07 & 0.35 & 0.04 \\ \text { Time } & 1 & 44.61 & <0.001 & 0.64 \\ \text { Electrode } & 2 & 35.44 & <0.001 & 0.57 \\ \text { Dose } \times \text { time } & 2 & 13.51 & <0.001 & 0.35 \\ \text { Dose } \times \text { electrode } & 4 & 3.03 & 0.04 & 0.11 \\ \text { Time } \times \text { electrode } & 2 & 3.32 & 0.06 & 0.12 \\ \text { Dose } \times \text { time } \times \text { electrode } & 4 & 1.66 & 0.19 & 0.06\end{array}$

NI - targets

$$
\begin{aligned}
& \text { Dose } \\
& \text { Time }
\end{aligned}
$$

Electrode

Dose $\times$ time

Dose $\times$ electrode

Time $\times$ electrode

Dose $\times$ time $\times$ electrode

(1)

$\begin{array}{rrrr}2 & 0.76 & 0.48 & 0.03 \\ 1 & 1.74 & 0.20 & 0.07 \\ 2 & 40.57 & <0.001 & 0.62 \\ 2 & 0.28 & 0.75 & 0.01 \\ 4 & 0.34 & 0.74 & 0.01 \\ 2 & 1.10 & 0.33 & 0.04 \\ 4 & 0.29 & 0.77 & 0.01\end{array}$

P3a-novels

$$
\begin{aligned}
& \text { Dose } \\
& \text { Time }
\end{aligned}
$$

Electrode

Dose $\times$ time

Dose $\times$ electrode

Time $\times$ electrode

Dose $\times$ time $\times$ electrode

$\begin{array}{lrcl}2 & 0.48 & 0.62 & 0.02 \\ 1 & 30.25 & <0.001 & 0.55 \\ 2 & 18.56 & <0.001 & 0.43 \\ 2 & 7.29 & 0.003 & 0.23 \\ 4 & 2.49 & 0.07 & 0.09 \\ 2 & 8.47 & 0.001 & 0.25 \\ 4 & 0.43 & 0.72 & 0.02\end{array}$

NI - novels

$\begin{array}{lllll}\text { Dose } & 2 & 0.44 & 0.64 & 0.02 \\ \text { Time } & 1 & 0.001 & 0.97 & 0.00 \\ \text { Electrode } & 2 & 8.25 & 0.004 & 0.25 \\ \text { Dose } \times \text { time } & 2 & 0.43 & 0.65 & 0.02 \\ \text { Dose } \times \text { electrode } & 4 & 0.59 & 0.63 & 0.02 \\ \text { Time } \times \text { electrode } & 2 & 0.90 & 0.38 & 0.04 \\ \text { Dose } \times \text { time } \times \text { electrode } & 4 & 0.53 & 0.60 & 0.02\end{array}$

Note: $p$-values reflect the results of the RMANOVAs with degrees of freedom corrected using the Greenhouse-Geisser correction. conducted for each PANSS subscale. The dose $\times$ time interaction was significant for PANSS positive (num $\mathrm{df}=3.41, \mathrm{ATS}=27.9, p<0.001$ ), negative (num $\mathrm{df}=3.78$, ATS $=13.19, \quad p<0.001$ ), and general (num $\mathrm{df}=3.2$, $\mathrm{ATS}=22.62, p<0.001)$ symptom subscales. For all three PANSS symptom subscales, post-hoc tests at the $10 \mathrm{~min}$ post-infusion time point revealed an identical pattern to that observed for PANSS total scores, such that scores in the placebo condition $<0.015 \mathrm{mg} / \mathrm{kg}$ THC $<0.03 \mathrm{mg} / \mathrm{kg}$ (all ps $<0.01$, see Table 3 ).

CADSS. The dose $\times$ time interaction was significant for the CADSS patient-rated (CADSS-PR) (num $\mathrm{df}=3.42$, $\mathrm{ATS}=20.1, p<0.001)$ and CADSS clinician-rated (CADSSCR) (num df $=3.42$, ATS $=20.3, p<0.001$ ) scores (Figure 6). All doses were significantly distinguished in a dosedependent manner at $10 \mathrm{~min}$ after infusion for both CADSS-PR and CADSS-CR (all $p<0.01$ ).

Visual Analog Scale (VAS) 'high'. The dose $\times$ time interaction was significant for VAS 'high' ratings (num $\mathrm{df}=2.99$, ATS $=28.5, p<0.001$ ) (Figure 6). Scores at $10 \mathrm{~min}$ after infusion were highest in the high-dose THC condition $(p s<0.01)$ and higher on the low-dose THC condition relative to the placebo condition $(p<0.001)$.

\section{Correlations Between ERP and Behavioral Measures}

Spearman's correlation coefficients were calculated to investigate associations between changes in PANSS and CADSS scores, and P300a/b amplitude and latency following $0.03 \mathrm{mg} / \mathrm{kg} \Delta 9$-THC infusion. For each variable, a change score was calculated as follows: difference score $=$ outcome at $10 \mathrm{~min}$ after infusion $(0.03 \mathrm{mg} / \mathrm{kg} \mathrm{THC})$ - outcome at $10 \mathrm{~min}$ after infusion (placebo). The $0.03 \mathrm{mg} / \mathrm{kg} \Delta 9-\mathrm{THC}$ condition was selected because the largest effects on ERPs and behavioral outcomes were observed in that condition. As shown in Table 4, THC-induced changes in P300b amplitude and THC-induced perceptual alterations measured by the CADSS-PR correlated significantly $\left(r_{s}=-0.43\right.$, $p<0.05)$. There were no other significant associations among ERP and symptom change scores. However, changes in PANSS and CADSS scores correlated highly overall (Table 4).

\section{Exploratory Analyses}

Additional exploratory analyses were conducted to determine the association between cannabis use in the 30 days

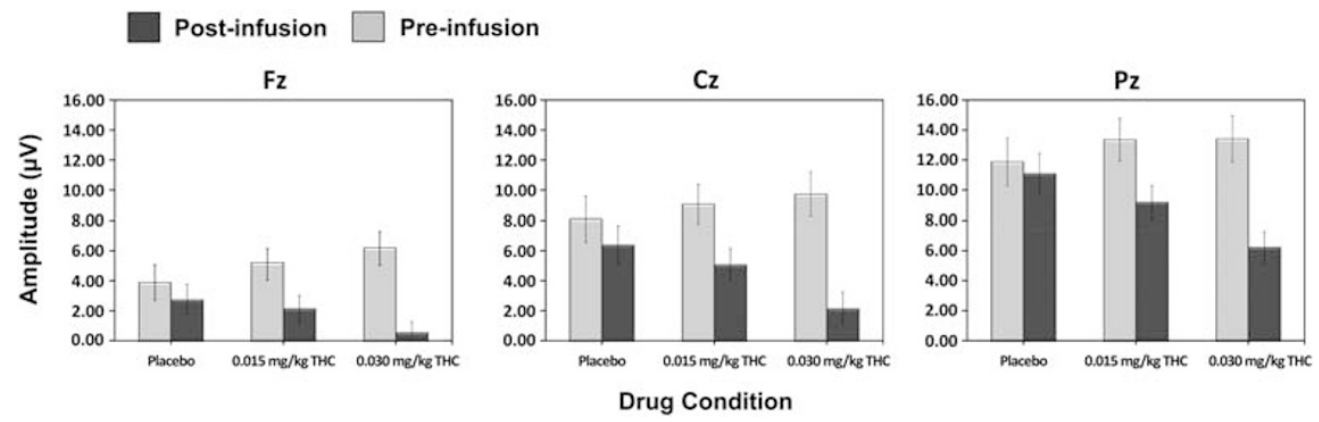

Figure 2 Mean $( \pm$ SEM) target P300b amplitudes for both the pre- and post-infusion electroencephalography (EEG) runs across dose conditions at electrodes $\mathrm{Fz}, \mathrm{Cz}$, and $\mathrm{Pz}$. 

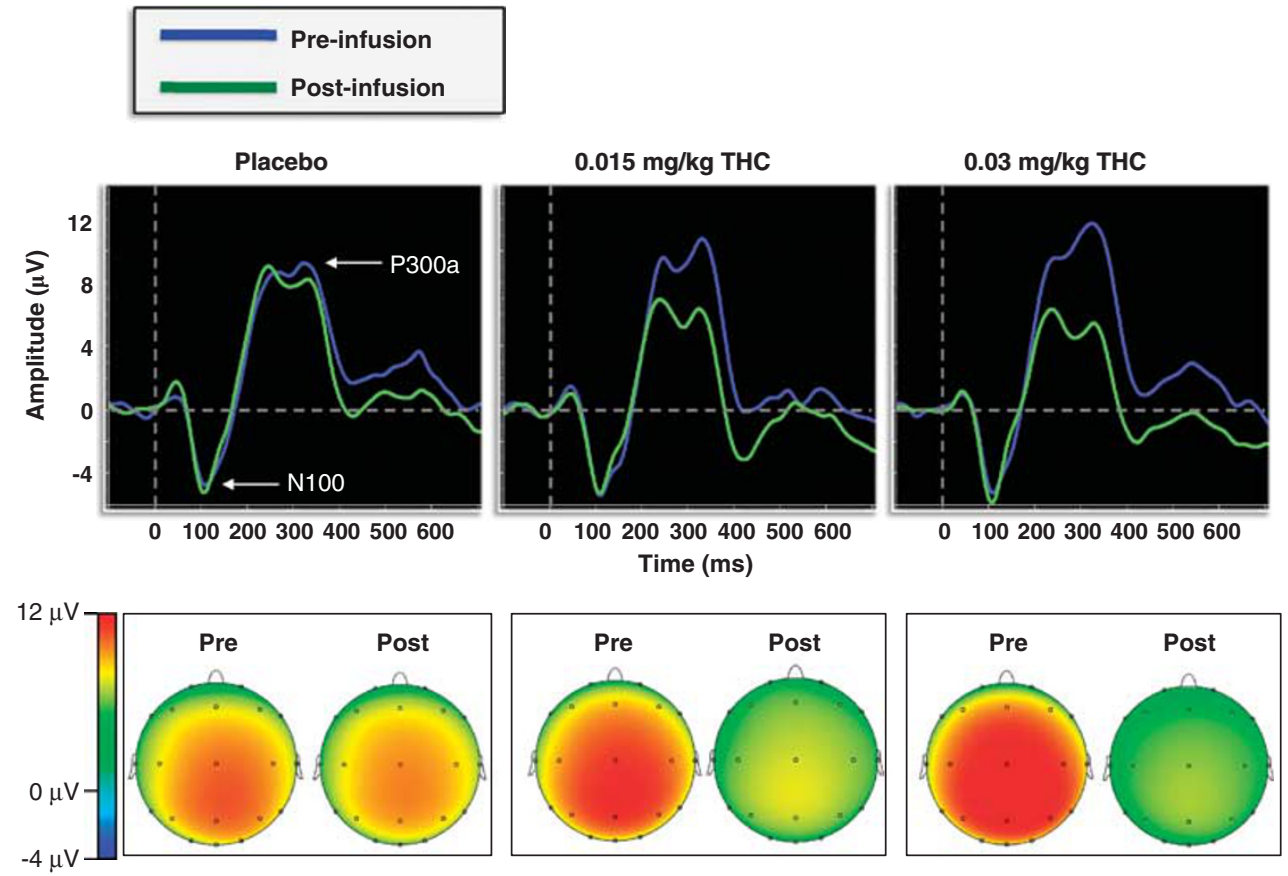

Figure 3 (Top) Grand-averaged novelty P300a waveforms at electrode Cz for both the pre- and post-infusion electroencephalography (EEG) runs across dose conditions. (Bottom) Topographic voltage maps from the peak grand-averaged P300a for both the pre- and post-infusion EEG runs across dose conditions.

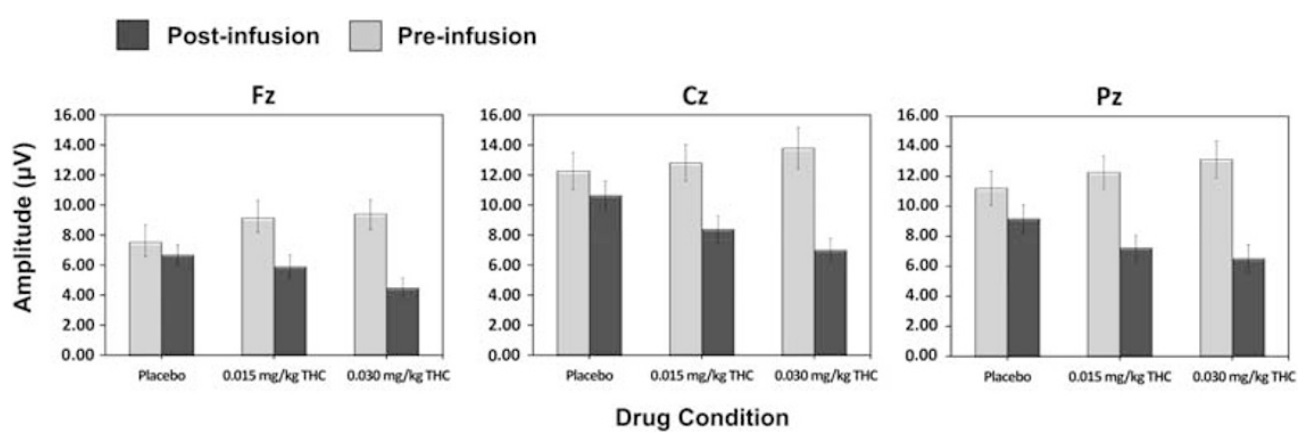

Figure 4 Mean ( \pm SEM) novelty P300a amplitudes for both the pre- and post-infusion electroencephalography (EEG) runs across dose conditions at electrodes Fz, Cz, and Pz.

prior to study participation and the effects of acute cannabis administration as measured by the EEG, and behavioral outcomes described above. The sample was divided into those who reported using cannabis in the past 30 days ('recent users', $n=14$ ) and those who did not ('non-recent users', $n=12$ ). Repeated-measures ANOVAs for ERP outcomes were conducted with the within-subjects factors dose (3) and time (2), and the between-subjects factor group (2) at the electrode site where the amplitude of the ERP of interest was largest (ie, at $\mathrm{Pz}$ for $\mathrm{P} 300 \mathrm{~b}$ and $\mathrm{Cz}$ for P300a). We did not investigate between-group differences in N100 amplitude or latency because these measures were not affected by $\Delta^{9}$-THC administration. The main effects and interactions of group are listed in the Supplementary Tables S1a and b. To summarize the results of the exploratory analyses, there was no main effect or interaction of group for P300b amplitude or latency ( $p s>0.13$ ), or for P300a amplitude $(p s>0.18)$. However, there was a significant main effect of group for P300a latency $(p<0.03)$, indicating that overall P300a peak latency was significantly shorter among recent users $v s$ non-recent users. For the behavioral data, nonparametric analyses revealed that recent cannabis users exhibited a blunted response to the perceptual-altering and psychotomimetic effects of $\Delta^{9}$-THC. Follow-up contrasts compared the responses of the groups at $10 \mathrm{~min}$ after infusion for both active THC dose conditions. Relative to non-recent users, recent users exhibited significantly lower scores on the PANSS total (num $\mathrm{df}=1, \mathrm{ATS}=4.38, p=$ 0.036 ), PANSS positive (num $\mathrm{df}=1, \mathrm{ATS}=4.96, p=0.026$ ), PANSS general (num $\mathrm{df}=1, \mathrm{ATS}=4.45, p=0.035$ ), CADSSCR (num $\mathrm{df}=1, \mathrm{ATS}=3.85, p=0.05$ ), and CADSS-PR (num $\mathrm{df}=1, \mathrm{ATS}=9.97, p=0.002$ ) at $10 \mathrm{~min}$ after infusion in the $0.03 \mathrm{mg} / \mathrm{kg} \Delta^{9}$-THC condition. There were no significant differences between the groups at $10 \mathrm{~min}$ after infusion in the $0.015 \mathrm{mg} / \mathrm{kg} \Delta^{9}$-THC condition for any of the behavioral measures $(p s>0.32)$. 
a Target N100s
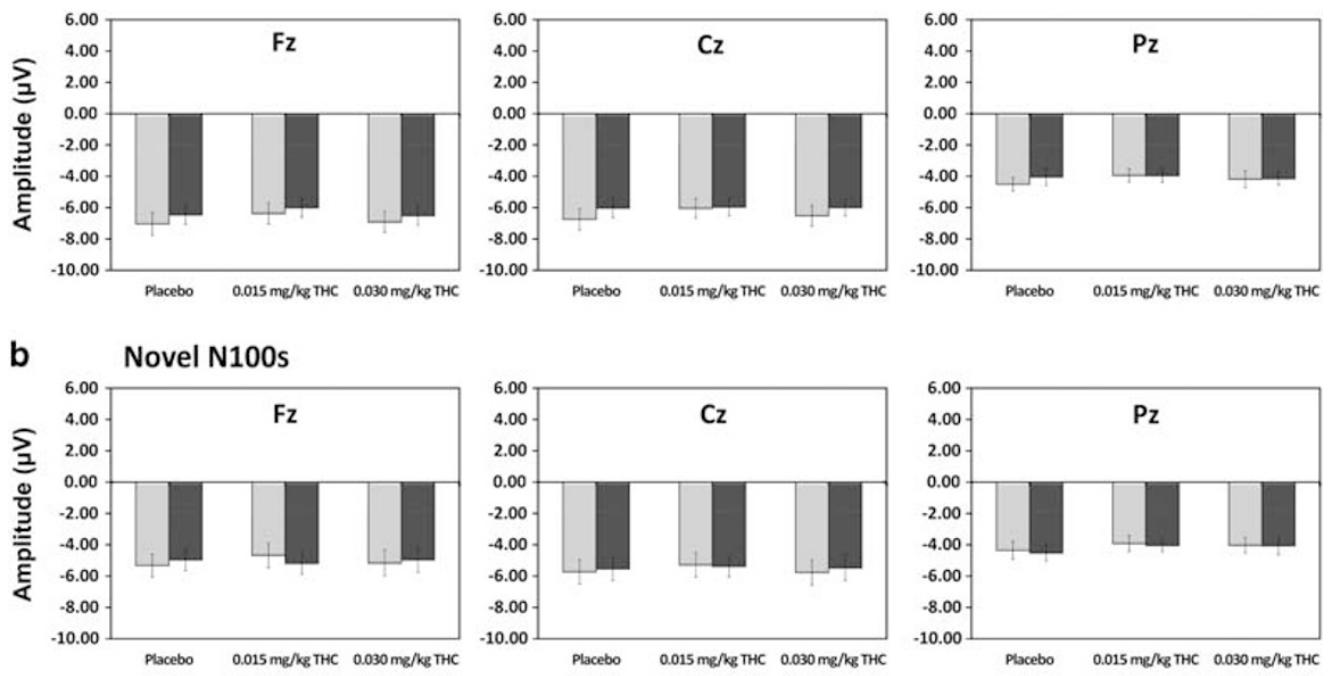

Pre-infusion $\square$ Post-infusion

Figure 5 (a) Mean ( \pm SEM) novelty NIO0 amplitudes for both the pre- and post-infusion electroencephalography (EEG) runs across dose conditions at electrodes Fz, Cz, and Pz. (b) Mean ( \pm SEM) novelty NIO0 amplitudes for both the pre- and post-infusion EEG runs across dose conditions at electrodes Fz, $\mathrm{Cz}$, and $\mathrm{Pz}$.

Table 3 Mean (SD) Scores on the PANSS, CADSS, and VAS Across Dose Condition and Time

\begin{tabular}{|c|c|c|c|c|c|c|c|c|c|}
\hline & \multicolumn{3}{|c|}{ Placebo } & \multicolumn{3}{|c|}{$0.015 \mathrm{mg} / \mathrm{kg}$ THC } & \multicolumn{3}{|c|}{$0.03 \mathrm{mg} / \mathrm{kg}$ THC } \\
\hline & Baseline & $+10 \mathrm{~min}$ & $+80 \mathrm{~min}$ & Baseline & $+10 \mathrm{~min}$ & $+80 \mathrm{~min}$ & Baseline & $+10 \mathrm{~min}$ & $+80 \mathrm{~min}$ \\
\hline \multicolumn{10}{|l|}{ PANSS } \\
\hline Positive & $7.42(1.06)$ & $7.96(2.18)$ & $7.23(0.5 \mathrm{I})$ & $7.31(0.68)$ & $10.73(2.65)$ & $8.38(1.77)$ & $7.08(0.27)$ & $12.65(3.19)$ & $9.46(2.37)$ \\
\hline Total & $29.77(3.35)$ & $32.65(5.38)$ & $30.12(2.44)$ & $28.96(1.18)$ & $40.62(7.39)$ & $33.12(5.01)$ & $28.92(1.60)$ & $50.04(10.52)$ & 37.88 (6.49) \\
\hline \multicolumn{10}{|l|}{ CADSS } \\
\hline$C R$ & $0.15(0.61)$ & $0.85(1.59)$ & $0.04(0.20)$ & $0.04(0.20)$ & $2.92(2.19)$ & $1.00(1.52)$ & $0.04(0.20)$ & $6.38(4.21)$ & $2.46(2.30)$ \\
\hline$P R$ & $0.08(0.39)$ & $0.77(2.4 I)$ & $0.31(0.88)$ & $0.12(0.33)$ & $3.65(4.15)$ & $2.31(3.60)$ & $0.00(0.00)$ & $9.69(10.20)$ & $4.92(6.19)$ \\
\hline
\end{tabular}

Abbreviations: CADSS, Clinician-Administered Dissociative Syndrome Scale; Clinician Rated (CR) and Patient Rated (PR); PANSS, Positive and Negative Syndrome Scale; VAS, Visual Analog Scale.

\section{Plasma THC and THC-COOH Levels}

There was a dose-dependent increase in plasma levels of THC and its metabolite THC-COOH across time (see Supplementary Figure S1).

\section{Safety Data}

No serious adverse events occurred with this study. There were five non-serious adverse events including nausea, vomiting, anxiety, and paranoia that occurred on test days. As reported elsewhere (Carbuto et al, 2011), safety follow-up at 1 and 3 months after the last test session did not reveal any evidence, suggestive of an increase in cannabis use.

\section{DISCUSSION}

To our knowledge, this is the first study to examine the effects of IV $\Delta^{9}$-THC on neural correlates of cognition using a traditional three-stimulus 'oddball' ERP paradigm. At doses that induced euphoria, psychosis-like effects and 

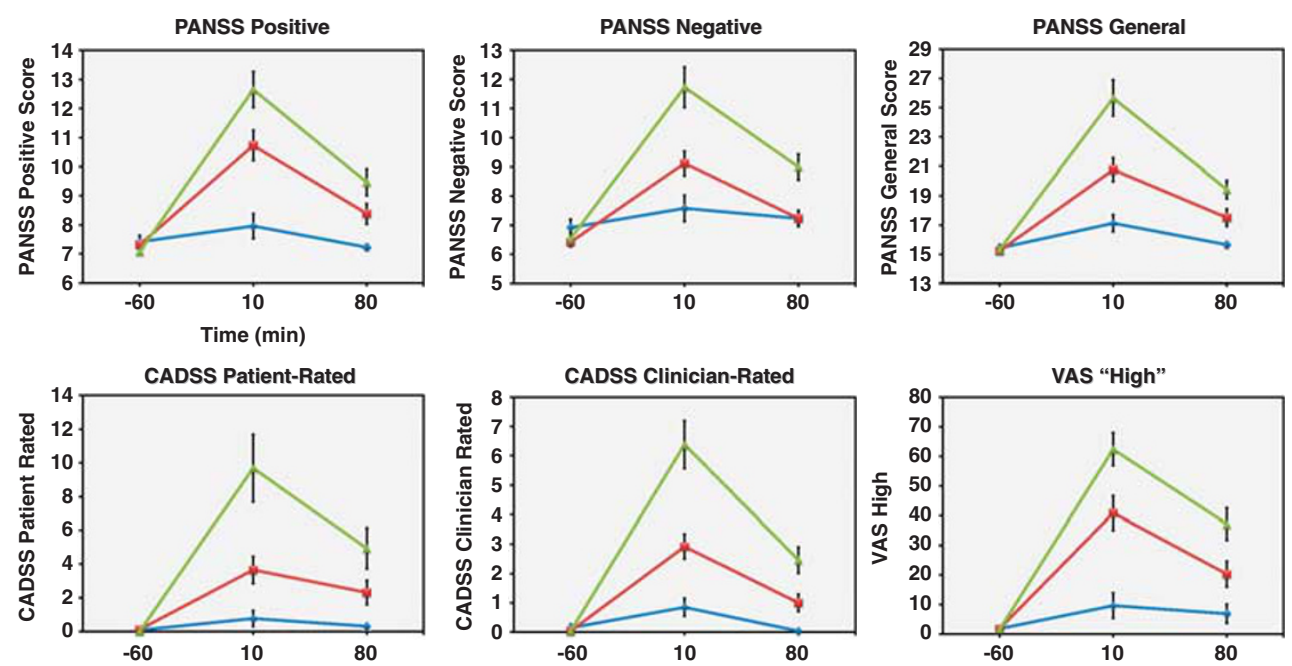

$\approx$ Placebo $=$ Low THC High THC

Figure 6 Mean $( \pm$ SEM) behavioral data for each drug condition at baseline $(-60 \mathrm{~min})$, peak $(+10 \mathrm{~min})$, and $-80 \mathrm{~min}$ time points.

Table 4 Spearman Correlations Among ERP and Symptom Change Scores

\begin{tabular}{|c|c|c|c|c|c|c|c|c|c|c|c|}
\hline & $\begin{array}{l}\text { Post-infusion difference score } \\
(0.03 \mathrm{mg} / \mathrm{kg} \text { THC - placebo) }\end{array}$ & I & 2 & 3 & 4 & 5 & 6 & 7 & 8 & 9 & 10 \\
\hline I & P3b amplitude & - & & & & & & & & & \\
\hline 3 & P3b latency & -0.013 & $-0.417 *$ & - & & & & & & & \\
\hline 4 & P3a latency & -0.255 & -0.89 & -0.218 & - & & & & & & \\
\hline 7 & PANSS general & -0.192 & -0.073 & -0.154 & 0.101 & $0.611 * * *$ & $0.617 * * *$ & - & & & \\
\hline 8 & PANSS total & -0.217 & -0.066 & -0.095 & 0.029 & $0.620 * *$ & $0.774 * *$ & $0.948 * *$ & - & & \\
\hline 9 & CADSS-CR & -0.055 & 0.220 & -0.135 & -0.015 & 0.340 & $0.685 * *$ & $0.812^{* * *}$ & $0.807 * *$ & - & \\
\hline 10 & CADSS-PR & $-\left.0.43\right|^{*}$ & 0.022 & -0.130 & 0.305 & $0.632 * *$ & $0.45 \mid *$ & 0.760 *** & $0.75 \mid * *$ & $0.622 * *$ & 一 \\
\hline
\end{tabular}

Note: ${ }^{\dagger} p<0.10$; $* p<0.05$; ${ }^{*} *$ $p<0.01$.

perceptual alterations, $\Delta^{9}$-THC dose-dependently reduced the amplitude of both the target $\mathrm{P} 300 \mathrm{~b}$ and the novelty P300a. However, $\Delta^{9}$-THC did not have any effect on the latency of either the P300b or P300a which may be at least partially attributable to the relatively poor test-retest reliability of the P300b latency measure. Moreover, $\Delta^{9}$ THC had no effects on the amplitude or latency of sensoryevoked ERPs preceding the P300a/b (the N100). Lastly, exploratory analysis examining cannabis use status showed that recent cannabis users had blunted behavioral effects to $\Delta^{9}$-THC. There were no significant effects of recent cannabis use on P300b amplitude, P300b latency, or P300 a amplitude, whereas P300a latency was significantly shorter overall among recent users relative to non-recent users.

\section{Target ERP Effects}

IV $\Delta^{9}$-THC dose-dependently reduced the amplitude of the target 'oddball' P300b, without affecting latency. This profile of effects is consistent with the published data using two-stimuli P300 paradigms (Bocker et al, 2010; Ilan et al, 2004; Roser et al, 2008). Amplitude of the P300b is thought to reflect attentional resource allocation, phasic attentional shifts, working memory updating of stimulus context, cognitive closure, and stimulus salience (Donchin and Coles, 1988; Knight and Scabini, 1998; Kramer and Strayer, 1988; Polich, 1989; Verleger et al, 2005). By contrast, latency of the P300b is thought to reflect cognitive processing speed or efficiency during stimulus evaluation, independent of motor preparation time (Duncan-Johnson and Donchin, 1977; McCarthy and Donchin, 1981). It therefore appears that in the auditory and visual modalities, acutely administered exogenous CB1R agonists have minimal effect on neural processing speed or efficiency, but instead disrupt higher cognitive processes relevant to target detection and stimulus evaluation.

In terms of the early sensory N100 component, IV $\Delta^{9}$ THC had no effect on either the amplitude or latency to 
target stimuli. The N100 is elicited by discrete auditory stimuli (eg, tones), is thought to be generated in the auditory cortex, and can be modulated by early attentional allocation (Coull, 1998; Hillyard et al, 1973). The current data therefore indicate that activation of CB1Rs does not affect early attentional/sensory processes (as indexed by the N100) during traditional 'oddball' tasks, but instead contributes to later, 'top-down' cognitive operations involved in target detection (as indexed by the P300b).

\section{Novelty ERP Effects}

This is the first report to our knowledge showing that $\Delta^{9}$ THC attenuates novelty P300a amplitude, and these effects are dose-dependent. No effects were observed on P300a latency. These data suggest that CB1Rs are involved in both bottom-up frontal circuits mediating orientation to novelty (P300a), and top-down temporal/parietal circuits mediating context updating and working memory (P300b). Indeed, we found no significant difference between the dose-dependent effects of THC on the amplitudes of the novelty P300a and the target P300b. This is not surprising, as discussed below the neural ensembles believed to be involved in generating the P300 are also regions known to be rich in CB1Rs (Eggan and Lewis, 2007). As endocannabinoids are neuromodulators, it is therefore possible that CB1R activation can disrupt both the P3a and P3b. Further, similar to target stimuli, $\Delta^{9}$-THC did not affect the early sensory N100 component to novel stimuli. Again, this suggests that activation of CB1Rs does not affect the early attentional/sensory processes, but instead contributes to longer latency mechanisms involved in the automatic orientation to novel stimuli (as indexed by the P300a).

\section{Neural Mechanisms}

Rather than being generated by a single neural source, it this thought that the P300 reflects activity from a distributed neural ensemble including such areas as the thalamus, hippocampus, inferior parietal lobe, superior temporal gyrus, and frontal cortex (Kiehl et al, 2001). Likewise, the P300a is thought to be mediated by a network of prefrontal, temporal, and parietal cortical sources (Halgren et al, 1998; Knight, 1996; Knight, 1984; Soltani and Knight, 2000). The neurochemistry of the P300a and P300b is believed to be at least partially dissociable (Polich and Criado, 2006; Watson et al, 2009). Catecholaminergic transmitters are known to influence the P300 (Nieuwenhuis et al, 2005; Polich, 2007; Polich and Criado, 2006; Turetsky and Fein, 2002). However, both the glutamatergic and GABAergic systems have been strongly implicated in the P300a/b (Frodl-Bauch et al, 1999; Javitt et al, 1995; Ray et al, 1992; Watson et al, 2009). For example, Watson et al, (2009), using a three-stimulus 'oddball' paradigm in the visual modality, demonstrated that both the NMDA antagonist ketamine and the $\mathrm{GABA}_{\mathrm{A}}$ agonist thiopental attenuated the amplitude of $\mathrm{P} 300 \mathrm{a} / \mathrm{b}$ (Watson et al, 2009). Interestingly, the effects of the $\mathrm{GABA}_{\mathrm{A}}$ agonist on P300 attenuation was greater than the NMDA antagonist ketamine. This is particularly germane to the effects of $\Delta^{9}$-THC on the P300, as it is now well established that CB1R activation in the cerebral cortex and hippocampus primarily affects the release of GABA, and to a lesser extent, glutamate (Ali and Todorova, 2010; Bacci et al, 2004; Bodor et al, 2005; Doherty and Dingledine, 2003; Eggan and Lewis, 2007; Eggan et al, 2010; Ferraro et al, 2001; Foldy et al, 2006; Hill et al, 2007; Katona et al, 2000; Maejima et al, 2001; Mereu et al, 2003; Wang, 2003). In fact, it is now recognized that ERPs like the P300 are generated by IPSPsand EPSPs, which are likely driven by the release of glutamate and GABA (Frodl-Bauch et al, 1999; Javitt et al, 1995; Luck et al, 2011; Ray et al, 1992). It is also well known that cannabinoids inhibit presynaptic neurotransmitter release in brain regions implicated in P300 generation (Eggan and Lewis, 2007; Freund et al, 2003; Glass et al, 1997). Hence, it is possible that acute $\Delta^{9}$-THC administration disrupts ERPs like the $\mathrm{P} 300 \mathrm{a} / \mathrm{b}$ by altering normal GABA and/or glutamate release in neural networks responsible for context updating, working memory, allocation of attentional resources, and the automatic orientation of attention. This could lead to perturbations in communication between brain regions involved in processing relevant sensory information (Lundqvist, 2005), or altered synchronization of neural networks (Skosnik et al, 2006). Indeed, these may represent a common neurochemical mechanism whereby exogenous cannabinoids cause abnormalities in normal cognitive/ perceptual function.

\section{Relationship to Behavior and Impact of Cannabis Exposure}

Replicating previous results from our group, the current study also showed that $\Delta^{9}$-THC induced psychotomimetic effects, perceptual alterations, and subjective 'high' in a dose-dependent manner, as assessed with the PANSS, CADSS, and VAS, respectively (D'Souza et al, 2004). $\Delta^{9}$ THC-induced reductions in P300b amplitude correlated with subject reported increase in perceptual alterations. Thus, at doses that induce subjective effects consistent with the behavioral profile of cannabis, $\Delta^{9}$-THC concurrently produced alterations in psychophysiological indices of information processing. No other correlations were observed between behavioral outcomes and ERP measures. The latter may be due to the fact that the current study may not have sufficient power to detect such associations. Although the reduction in P300 amplitude is a robust finding in schizophrenia, the relationship between clinical variables and P300 deficits is mixed. Some but not other studies have found correlations between clinical symptoms and the auditory P300 (Blackwood et al, 1987; Egan et al, 1994; Higashima et al, 1998; Kawasaki et al, 1994; Mathalon et al, 2000; Merrin and Floyd, 1994; Saitoh et al, 1984; St Clair et al, 1989). Finally, the neural substrates governing the behavioral $v s$ psychophysiological effects of cannabinoids may differ, thus accounting for the general absence of association between the behavioral changes and P300 deficits induced by THC.

The current experiment also demonstrated that individuals with a recent history of cannabis use had blunted responses to the behavioral effects of $\Delta^{9}$-THC. This also replicates previous results (D'Souza et al, 2008b), and is likely related to the known tolerance and CB1R downregulation that occurs after repeated cannabis exposure (Haney et al, 1999; Hirvonen et al, 2011; Villares, 2007). Interestingly, recent cannabis use did not influence the 
disruptive effects of $\Delta^{9}$-THC to disrupt the $\mathrm{P} 300 \mathrm{a} / \mathrm{b}$ response. The reason for this discrepancy is unclear. As mentioned above, one possible explanation is that distinct neural circuits may be responsible for the behavioral $v s$ psychophysiological effects of THC. Another possible explanation is that, because of the relatively small sample sizes of recent and non-recent users, and the wide variation in the frequency of cannabis use within the recent user group (see Table 1), we did not have the power to detect a reliable effect of recent cannabis use on ERP outcomes.

\section{Strengths, limitations, and conclusions}

The IV route of administration and the weight-adjusted dose is distinct from previous studies, and addresses the inter- and intra-individual variability associated with oral or smoked $\Delta^{9}$-THC. The use of multiple doses allows for establishing a dose-response relationship. The inclusion of subjects with little exposure to cannabis is distinct from previous studies, and this allows one to characterize $\Delta^{9}$ THC effects in the absence of any exposure-related tolerance of CB1R function. Furthermore, in contrast to previous studies, this study did not include any heavy users of cannabis, a group who generally show blunted responses to the acute effects of $\Delta^{9}$-THC. In terms of limitations, this study was not designed to discriminate the contributions of tolerance and innate differences to the group differences observed. Also, as subjects did not respond to the novel stimuli in any way, it was impossible to directly determine whether novelty-processing speed was affected by $\Delta^{9}$-THC.

In summary, this study revealed dose-dependent effects of $\Delta^{9}$-THC on ERP correlates of attention to novelty, stimulus detection, and working memory (the P300a/b), but not early sensory processes (ie, the N100). The results also confirm dose-dependent effects of $\Delta^{9}$-THC on psychotomimetic effects, perceptual alterations, and subjective 'high', as reported previously by our group. Exploratory analyses examining the magnitude of recent cannabis exposure revealed a differential pattern of outcomes on the behavioral assessments, but not the ERP measures. Taken together, these data suggest that cannabinoid agonists may disrupt cortical processes responsible for context updating and the automatic orientation of attention, while leaving processing speed and earlier sensory ERP components intact.

\section{ACKNOWLEDGEMENTS}

We acknowledge support from the (1) Department of Veterans Affairs, (2) National Institute of Mental Health, (3) National Institute of Drug Abuse, (4) National Institute of Alcoholism and Alcohol Abuse (NIAAA), and (5) the Yale Center for Clinical Investigation (YCCI). This research project was funded in part by grants from NIDA (R21 DA020750 to DCD) and a NARSAD Young Investigator Award to PDS. We also thank Angelina Genovese, RNC, MBA; Michelle San Pedro, RN; Elizabeth O’Donnell, RN; Brenda Breault, RN, BSN; Sonah Yoo, RPh; Rachel Galvan, $\mathrm{RPh}$; and Willie Ford of the Neurobiological Studies Unit at the VA Connecticut Healthcare System, West Haven
Campus for their central contributions to the success of this project.

\section{DISCLOSURE}

Daniel Fridberg, Patrick Skosnik, Ashley Williams, Brian Roach, Nagendra Singh, Michelle Carbuto, Jacqueline Elander, Ashley Schnakenberg, Brian Pittman, and Andrew Sewell report no financial relationships with commercial interests. Dr Mathalon reports research funding from AstraZeneca, Inc, consulting fees from Pfizer, Inc., and that his name is included under a provisional patent titled 'A non-invasive biomarker of human cortical plasticity and cognition', USPTO serial number 61/140833. Mohini Ranganathan has in the past 3 years or currently receives research grant support administered through Yale University School of Medicine from Eli Lilly. Deepak Cyril D'Souza has in the past 3 years or currently receives research grant support administered through Yale University School of Medicine from Astra Zeneca, Abbott Laboratories, Eli Lilly, Organon, Pfizer, and Sanofi; he is a consultant for Bristol Meyers Squibb.

\section{REFERENCES}

Ali AB, Todorova M (2010). Asynchronous release of GABA via tonic cannabinoid receptor activation at identified interneuron synapses in rat CA1. Eur J Neurosci 31: 1196-1207.

Azorlosa JL, Greenwald MK, Stitzer ML (1995). Marijuana smoking: effects of varying puff volume and breathhold duration. J Pharmacol Exp Ther 272: 560-569.

Azorlosa JL, Heishman SJ, Stitzer ML, Mahaffey JM (1992). Marijuana smoking: effect of varying delta 9-tetrahydrocannabinol content and number of puffs. J Pharmacol Exp Ther 261: 114-122.

Bacci A, Huguenard JR, Prince DA (2004). Long-lasting selfinhibition of neocortical interneurons mediated by endocannabinoids. Nature 431: 312-316.

Bhattacharyya S, Morrison PD, Fusar-Poli P, Martin-Santos R, Borgwardt S, Winton-Brown T et al (2010). Opposite effects of delta-9-tetrahydrocannabinol and cannabidiol on human brain function and psychopathology. Neuropsychopharmacology 35: 764-774.

Blackwood DH, Whalley LJ, Christie JE, Blackburn IM, St Clair DM, McInnes A (1987). Changes in auditory P3 event-related potential in schizophrenia and depression. Br J Psychiatry 150: 154-160.

Bocker KB, Gerritsen J, Hunault CC, Kruidenier M, Mensinga TT, Kenemans JL (2010). Cannabis with high delta9-THC contents affects perception and visual selective attention acutely: an event-related potential study. Pharmacol Biochem Behav 96: 67-74.

Bodor AL, Katona I, Nyiri G, Mackie K, Ledent C, Hajos $\mathrm{N}$ et al (2005). Endocannabinoid signaling in rat somatosensory cortex: laminar differences and involvement of specific interneuron types. J Neurosci 25: 6845-6856.

Bremner JD, Krystal JH, Putnam FW, Southwick SM, Marmar C, Charney DS et al (1998). Measurement of dissociative states with the Clinician-Administered Dissociative States Scale (CADSS). J Traum Stress 11: 125-136.

Brunner E, Domhof S, Langer F (2002). Nonparametric Analysis of Longitudinal Data in Factorial Experiments. John Wiley \& Sons: New York, NY.

Carbuto M, Sewell RA, Williams A, Forselius-Bielen K, Braley G, Elander J et al (2011). The safety of studies with intravenous 
Delta(9)-tetrahydrocannabinol in humans, with case histories. Psychopharmacology (Berl) 219: 885-896.

Clarke JM, Halgren E, Chauvel P (1999). Intracranial ERPs in humans during a lateralized visual oddball task: I. occipital and peri-rolandic recordings. Clin Neurophysiol 110: 12101225.

Cohen J (1973). Eta-squared and partial Eta-squared in communication science. Hum Comm Res 28: 473-490.

Coull JT (1998). Neural correlates of attention and arousal: insights from electrophysiology, functional neuroimaging and psychopharmacology. Prog Neurobiol 55: 343-361.

D’Souza DC, Braley G, Blaise R, Vendetti M, Oliver S, Pittman B et al (2008a). Effects of haloperidol on the behavioral, subjective, cognitive, motor, and neuroendocrine effects of Delta-9-tetrahydrocannabinol in humans. Psychopharmacology (Berl) 198: 587-603.

D’Souza DC, Perry E, MacDougall L, Ammerman Y, Cooper T, $\mathrm{Wu} \mathrm{YT}$ et al (2004). The psychotomimetic effects of intravenous delta-9-tetrahydrocannabinol in healthy individuals: implications for psychosis. Neuropsychopharmacology 29: 1558-1572.

D’Souza DC, Ranganathan M, Braley G, Gueorguieva R, Zimolo Z, Cooper $\mathrm{T}$ et al (2008b). Blunted psychotomimetic and amnestic effects of delta-9-tetrahydrocannabinol in frequent users of cannabis. Neuropsychopharmacology 33: 2505-2516.

de Sola S, Tarancon T, Pena-Casanova J, Espadaler JM, Langohr K, Poudevida S et al (2008). Auditory event-related potentials (P3) and cognitive performance in recreational ecstasy polydrug users: evidence from a 12-month longitudinal study. Psychopharmacology (Berl) 200: 425-437.

Doherty J, Dingledine R (2003). Functional interactions between cannabinoid and metabotropic glutamate receptors in the central nervous system. Curr Opin Pharmacol 3: 46-53.

Donchin E, Coles M (1988). Is the P300 component a manifestation of context updating? (Commentary on Verleger's critique of the context updating model). Behav Brain Sci 11: 357-374.

Duncan-Johnson CC, Donchin E (1977). On quantifying surprise: the variation in event-related potentials with subjective probability. Psychophysiology 14: 456-467.

Egan MF, Duncan CC, Suddath RL, Kirch DG, Mirsky AF, Wyatt RJ (1994). Event-related potential abnormalities correlate with structural brain alterations and clinical features in patients with chronic schizophrenia. Schizophr Res 11: 259-271.

Eggan SM, Lewis DA (2007). Immunocytochemical distribution of the cannabinoid $\mathrm{CB} 1$ receptor in the primate neocortex: a regional and laminar analysis. Cereb Cortex 17: 175-191.

Eggan SM, Melchitzky DS, Sesack SR, Fish KN, Lewis DA (2010). Relationship of cannabinoid CB1 receptor and cholecystokinin immunoreactivity in monkey dorsolateral prefrontal cortex. Neuroscience 169: 1651-1661.

Ferraro L, Tomasini MC, Gessa GL, Bebe BW, Tanganelli S, Antonelli T (2001). The cannabinoid receptor agonist WIN $55,212-2$ regulates glutamate transmission in rat cerebral cortex: an in vivo and in vitro study. Cereb Cortex 11: 728-733.

First MB, Spitzer RL, Gibbon M, Williams JBW (2002). Structured Clinical Interview for DSM-IV-TR Axis I DisordersNon-patient Edition. American Psychiatric Association: Washington, DC.

Foldy C, Neu A, Jones MV, Soltesz I (2006). Presynaptic, activitydependent modulation of cannabinoid type 1 receptor-mediated inhibition of GABA release. J Neurosci 26: 1465-1469.

Fowler JS, Volkow ND, Wang GJ, Pappas N, Logan J, MacGregor R et al (1998). Neuropharmacological actions of cigarette smoke: brain monoamine oxidase B (MAO B) inhibition. J Addict Dis 17: 23-34.

Freund TF, Katona I, Piomelli D (2003). Role of endogenous cannabinoids in synaptic signaling. Physiol Rev 83: 1017-1066.
Friedman D, Simpson G, Hamberger M (1993). Age-related changes in scalp topography to novel and target stimuli. Psychophysiology 30: 383-396.

Frodl-Bauch T, Bottlender R, Hegerl U (1999). Neurochemical substrates and neuroanatomical generators of the event-related P300. Neuropsychobiology 40: 86-94.

Glass M, Dragunow M, Faull RL (1997). Cannabinoid receptors in the human brain: a detailed anatomical and quantitative autoradiographic study in the fetal, neonatal and adult human brain. Neuroscience 77: 299-318.

Gratton G, Coles MG, Donchin E (1983). A new method for off-line removal of ocular artifact. Electroencephalogr Clin Neurophysiol 55: $468-484$.

Grotenhermen F (2003). Pharmacokinetics and pharmacodynamics of cannabinoids. Clin Pharmacokinet 42: 327-360.

Guillem K, Vouillac C, Azar MR, Parsons LH, Koob GF, Cador M et al (2005). Monoamine oxidase inhibition dramatically increases the motivation to self-administer nicotine in rats. J Neurosci 25: 8593-8600.

Halgren E, Marinkovic K, Chauvel P (1998). Generators of the late cognitive potentials in auditory and visual oddball tasks. Electroencephalogr Clin Neurophysiol 106: 156-164.

Haney M, Ward AS, Comer SD, Foltin RW, Fischman MW (1999). Abstinence symptoms following oral THC administration to humans. Psychopharmacology (Berl) 141: 385-394.

Hart CL, Ilan AB, Gevins A, Gunderson EW, Role K, Colley J et al (2010). Neurophysiological and cognitive effects of smoked marijuana in frequent users. Pharmacol Biochem Behav 96: 333-341.

Higashima M, Urata K, Kawasaki Y, Maeda Y, Sakai N, Mizukoshi $\mathrm{C}$ et al (1998). P300 and the thought disorder factor extracted by factor-analytic procedures in schizophrenia. Biol Psychiatry 44: 115-120.

Hill EL, Gallopin T, Ferezou I, Cauli B, Rossier J, Schweitzer P et al (2007). Functional CB1 receptors are broadly expressed in neocortical GABAergic and glutamatergic neurons. J Neurophysiol 97: 2580-2589.

Hillyard SA, Hink RF, Schwent VL, Picton TW (1973). Electrical signs of selective attention in the human brain. Science 182: 177-180.

Hirvonen J, Goodwin RS, Li CT, Terry GE, Zoghbi SS, Morse C et al (2011). Reversible and regionally selective downregulation of brain cannabinoid $\mathrm{CB}(1)$ receptors in chronic daily cannabis smokers. Mol Psychiatry; e-pub ahead of print 12 July 2011.

Ilan AB, Gevins A, Coleman M, Elsohly MA, de Wit H (2005). Neurophysiological and subjective profile of marijuana with varying concentrations of cannabinoids. Behav Pharmacol 16: 487-496.

Ilan AB, Smith ME, Gevins A (2004). Effects of marijuana on neurophysiological signals of working and episodic memory. Psychopharmacology (Berl) 176: 214-222.

Javitt DC, Schroeder CE, Steinschneider M, Arezzo JC, Ritter W, Vaughan Jr HG (1995). Cognitive event-related potentials in human and non-human primates: implications for the PCP/ NMDA model of schizophrenia. Electroencephalogr Clin Neurophysiol Suppl 44: 161-175.

Jeon YW, Polich J (2003). Meta-analysis of P300 and schizophrenia: patients, paradigms, and practical implications. Psychophysiology 40: 684-701.

Katona I, Sperlagh B, Magloczky Z, Santha E, Kofalvi A, Czirjak S et al (2000). GABAergic interneurons are the targets of cannabinoid actions in the human hippocampus. Neuroscience 100: 797-804.

Kawasaki Y, Maeda Y, Sakai N, Higashima M, Urata K, Yamaguchi N et al (1994). Evaluation and interpretation of symptom structures in patients with schizophrenia. Acta Psychiatr Scand 89: 399-404.

Kay SR, Opler LA, Lindenmayer JP (1989). The Positive and Negative Syndrome Scale (PANSS): rationale and standardisation. Br J Psychiatry (Suppl 7): 59-67. 
Kempel P, Lampe K, Parnefjord R, Hennig J, Kunert HJ (2003). Auditory-evoked potentials and selective attention: different ways of information processing in cannabis users and controls. Neuropsychobiology 48: 95-101.

Kiehl KA, Laurens KR, Duty TL, Forster BB, Liddle PF (2001). Neural sources involved in auditory target detection and novelty processing: an event-related fMRI study. Psychophysiology 38: $133-142$.

Knight R (1996). Contribution of human hippocampal region to novelty detection. Nature 383: 256-259.

Knight RT (1984). Decreased response to novel stimuli after prefrontal lesions in man. Electroencephalogr Clin Neurophysiol 59: 9-20.

Knight RT, Scabini D (1998). Anatomic bases of event-related potentials and their relationship to novelty detection in humans. J Clin Neurophysiol 15: 3-13.

Kramer AF, Strayer DL (1988). Assessing the development of automatic processing: an application of dual-task and eventrelated brain potential methodologies. Biol Psychol 26: 231-267.

Lichtman AH, Martin BR (2005). Cannabinoid tolerance and dependence. Handb Exp Pharmacol 168: 691-717.

Luck SJ, Mathalon DH, O’Donnell BF, Hamalainen MS, Spencer KM, Javitt DC et al (2011). A roadmap for the development and validation of event-related potential biomarkers in schizophrenia research. Biol Psychiatry 70: 28-34.

Lundqvist T (2005). Cognitive consequences of cannabis use: comparison with abuse of stimulants and heroin with regard to attention, memory and executive functions. Pharmacol Biochem Behav 81: 319-330.

Maejima T, Hashimoto K, Yoshida T, Aiba A, Kano M (2001). Presynaptic inhibition caused by retrograde signal from metabotropic glutamate to cannabinoid receptors. Neuron 31: 463-475.

Marti F, Arib O, Morel C, Dufresne V, Maskos U, Corringer PJ et al (2011). Smoke extracts and nicotine, but not tobacco extracts, potentiate firing and burst activity of ventral tegmental area dopaminergic neurons in mice. Neuropsychopharmacology 36: 2244-2257.

Mathalon DH, Ford JM, Pfefferbaum A (2000). Trait and state aspects of P300 amplitude reduction in schizophrenia: a retrospective longitudinal study. Biol Psychiatry 47: 434-449.

Mathalon DH, Hoffman RE, Watson TD, Miller RM, Roach BJ, Ford JM (2010). Neurophysiological distinction between schizophrenia and schizoaffective disorder. Front Hum Neurosci 3: 70 .

McCarthy G, Donchin E (1981). A metric for thought: a comparison of P300 latency and reaction time. Science 211: 77-80.

Mereu G, Fa M, Ferraro L, Cagiano R, Antonelli T, Tattoli M et al (2003). Prenatal exposure to a cannabinoid agonist produces memory deficits linked to dysfunction in hippocampal longterm potentiation and glutamate release. Proc Natl Acad Sci USA 100: 4915-4920.

Merrin EL, Floyd TC (1994). P300 responses to novel auditory stimuli in hospitalized schizophrenic patients. Biol Psychiatry 36: $527-542$.

Nieuwenhuis S, Aston-Jones G, Cohen JD (2005). Decision making, the P3, and the locus coeruleus-norepinephrine system. Psychol Bull 131: 510-532.

ONDCP, O. o. N. D. C. P. (2008). Marijuana: The Greatest Cause of Illegal Drug Abuse. The Marijuana Factbook. Executive Office of the President: Washington, DC. 20503.

Patrick G, Straumanis JJ, Struve FA, Fitz-Gerald MJ, Manno JE (1997). Early and middle latency evoked potentials in medically and psychiatrically normal daily marihuana users: a paucity of significant findings. Clin Electroencephal 28: 26-31.
Patrick G, Straumanis JJ, Struve FA, Nixon F, Fitz-Gerald MJ, Manno JE et al (1995). Auditory and visual P300 event related potentials are not altered in medically and psychiatrically normal chronic marihuana users. Life Sciences 56: 2135-2140.

Polich J (1989). Habituation of P300 from auditory stimuli. Psychobiology 17: 19-28.

Polich J (2007). Updating P300: an integrative theory of P3a and P3b. Clin Neurophysiol 118: 2128-2148.

Polich J, Criado JR (2006). Neuropsychology and neuropharmacology of P3a and P3b. Int J Psychophysiol 60: 172-185.

Porjesz B, Rangaswamy M, Kamarajan C, Jones KA, Padmanabhapillai A, Begleiter H (2005). The utility of neurophysiological markers in the study of alcoholism. Clin Neurophysiol 116: 993-1018.

Ramaekers JG, Kauert G, Theunissen EL, Toennes SW, Moeller MR (2009). Neurocognitive performance during acute THC intoxication in heavy and occasional cannabis users. J Psychopharmacol 23: 266-277.

Ranganathan M, D'Souza DC (2006). The acute effects of cannabinoids on memory in humans: a review. Psychopharmacology (Berl) 188: 425-444.

Ray PG, Meador KJ, Loring DW (1992). Diazepam effects on the P3 event-related potential. J Clin Psychopharmacol 12: 415-419.

Roser P, Juckel G, Rentzsch J, Nadulski T, Gallinat J, Stadelmann AM (2008). Effects of acute oral Delta(9)-tetrahydrocannabinol and standardized cannabis extract on the auditory P300 event-related potential in healthy volunteers. Eur Neuropsychopharmacol 18: 569-577.

Saitoh O, Niwa S, Hiramatsu K, Kameyama T, Rymar K, Itoh K (1984). Abnormalities in late positive components of eventrelated potentials may reflect a genetic predisposition to schizophrenia. Biol Psychiatry 19: 293-303.

SAMHSA, (2011). Results from the 2010 National Survey on Drug Use and Health: Summary of National Findings. Substance Abuse and Mental Health Services Administration: Rockville, MD.

Sewell RA, Skosnik PD, Garcia-Sosa I, Ranganathan M, D’Souza DC (2010). Behavioral, cognitive and psychophysiological effects of cannabinoids: relevance to psychosis and schizophrenia. Rev Bras Psiquiatr 32(Suppl 1): S15-S30.

Shaw LM, Edling-Owens J, Mattes R (1991). Ultrasensitive measurement of delta-9-tetrahydrocannabinol with a high energy dynode detector and electron-capture negative chemical-ionization mass spectrometry. Clin Chem 37: 2062-2068.

Skosnik PD, Krishnan GP, Aydt EE, Kuhlenshmidt HA, O’Donnell BF (2006). Psychophysiological evidence of altered neural synchronization in cannabis use: relationship to schizotypy. Am J Psychiatry 163: 1798-1805.

Skosnik PD, Park S, Dobbs L, Gardner WL (2008). Affect processing and positive syndrome schizotypy in cannabis users. Psychiatry Res 157: 279-282.

Solowij N, Michie PT, Fox AM (1991). Effects of long-term cannabis use on selective attention: an event-related potential study. Pharmacol Biochem Behav 40: 683-688.

Solowij N, Michie PT, Fox AM (1995). Differential impairments of selective attention due to frequency and duration of cannabis use. Biol Psychiatry 37: 731-739.

Soltani M, Knight RT (2000). Neural origins of the P300. Crit Rev Neurobiol 14: 199-224.

St Clair D, Blackwood D, Muir W (1989). P300 abnormality in schizophrenic subtypes. J Psychiatr Res 23: 49-55.

Stadelmann AM, Juckel G, Arning L, Gallinat J, Epplen JT, Roser P (2011). Association between a cannabinoid receptor gene (CNR1) polymorphism and cannabinoid-induced alterations of the auditory event-related P300 potential. Neurosci Lett 496: 60-64. 
Turetsky BI, Fein G (2002). Alpha2-noradrenergic effects on ERP and behavioral indices of auditory information processing. Psychophysiology 39: 147-157.

Verleger R, Jaskowski P, Wascher E (2005). Evidence for an integrative role of P3b in linking reaction to perception. J Psychophysiol 19: 165-181.

Villares J (2007). Chronic use of marijuana decreases cannabinoid receptor binding and mRNA expression in the human brain. Neuroscience 145: 323-334.
Wang SJ (2003). Cannabinoid CB1 receptor-mediated inhibition of glutamate release from rat hippocampal synaptosomes. Eur $\mathrm{J}$ Pharmacol 469: 47-55.

Watson TD, Petrakis IL, Edgecombe J, Perrino A, Krystal JH, Mathalon DH (2009). Modulation of the cortical processing of novel and target stimuli by drugs affecting glutamate and GABA neurotransmission. Int $J$ Neuropsychopharmacol 12: 357-370.

Supplementary Information accompanies the paper on the Neuropsychopharmacology website (http://www.nature.com/npp) 